EIIRPATION OF AN OSSEOUS TUMOUR FROM TIIE ORBIT.

$\downarrow$ GIRt, about 17 years of age, received a bow with a rake, the handle of which enteid the leit olbit; she immediately fell lown insensible, but soon recovered her strises, and on examination a deep wound rns found between the upper paries of the orbit and the eye, the upper eyelid having hen lacerated ; there was not much bamorflase, and the eye did not seem to be affecteti, and remained free from infiammation during the healing of the wound, which took place within a short time, and without any particular treatment. About eighteen months ater the accident the girl, who in other respects was perfectly well, felt a tumour frrming below the upper eyelid, but as it ras not accompanied by pain or any other inconrenience, she did not do any-thing for it until the tumour had acquired a large rolume. At the time when Dr. Salzer saw her, it was four years from the occurrence 0 i the accident; the tumour was seen very hard, immoreable, and protruded through the orbit, but was still completely covered by the eyelid; the globe of the eye was furcibly pushed aside and downwards, so as ulmost to touch the left nostril ; sight was not completely destroyed. The upper eyelid was divided, and the tumour having been laid bare in its whole breadth, was found to be of osseous tissue and attached to the olbit, but not as was anticipated by a pedicle, but by a broad base. The substance of the morbid growth was so dense as to render the application quite ineffectual, and it ras actually found necessary to use a hammer and chisel to remove only portions of it. Towards the end of the operation, which lasted several hours, it appeared that a large pece of bone was loose, but this could not be extracted, though several attempts were made. The patient was bled, and had ice afplied over the forehead; she complained of violent pain, apparently from the pressure which the loose piece of bone exerted on the eye; for as soon as by a proper appratus this pressure was lessened, the pain and intlammatory symptoms subsided. The usseous fragment, and what remained of the exostosis, having been subsequently remored by the application of the trephine, thw muscles and vessels of the eye were fund to have been so much flattened as ¿most to resemble ligaments; however, irter some time the globe began gradually 1. reascend in to the orbit, and in six weeks aiter the operation recovered its natural Inition; the sight had not suffered at all. lihe quantity of bone removed, after having $b_{j}<n$ dried, weighed about two ounces.lene Zeitschr.f. Nat. u. Heilk.
LITHOTOMY IN EGY PT.

It appears that urinary calculus is very frequent in Egypt, for during a residence of four years in that country M. Clot, chief surgeon of the hospital Aboa Zabel (of which we made mention in a former number), has witnessed sixty operations, of which he himself performed forty. From his report on this subject, it appears that of forty patients on whom the operation was performed, two only died; of the others, eleven were cured between the 7 th and 10 th day; sixteen between the 11 th and 20 th ; eight between the 22 nd and 30 th ; four between the 32 nd and 40 th; and one on the 50 th day after the operation. In three cases of five, in which Varra's method was employed, a recto-vesical fistula remained; in twentyfour, the lateral operation was performed; and in sixteen, the section was made through the raphe. This extraordinary success is perhaps principally to be accounted for by the mildness of a climate in which all wounds heal very easily, and by the absence of all tendency to inflammatiou in most of the individuals operated upon, two circum stances which have already been remarked by some of the surgeons of the French expedition, and particularly by M. Larrey himself.-Lanc. Franç.

\section{ON THE DETECTION OF LEAD.}

\section{To the Edilor of The Lancet.}

Sin,-On reading a late $N_{u m b e r}$ of $\Gamma_{H E}$ LANCET, I find that Dr. Christison recommends the employment of hydriodate of potash as a test for lead and its preparations; and that although he does notice the important objection against its use, yet he does not, as you justly observe, pay it that " special attention which the strictness of their investigations demands." Of course I allude to the property which uitric acid possesses of striking a yellow colour with hydrio. date of potash, very similar to that produced by the action of hydriodate of potash on the salts of lead. As, however, under particular circumstances, this test is perfectly free from fallacy, I shall trouble you with the plan which I consider best calculated for the detection of small quantities of lead by means of hydriodate of potash, should that reagent be selected; not that I am foolish enough to claim the merit of an original investigation, for 1 am well aware that the facts I am about to state must be familiar to every chemist. Obtain a sulphuret of lead by the action of sulphuretted hydrogen gas, decompose this sulphuret by nitric acid, thus obtaining a nitrate of lead, following thus far the directions of Dr. Christison, and then, instead of apply. 
ing hydriodate of potash, add to a solution of the nitrate of lead, a solution of carbonate of soda ; a carbonate of lead will be precipitated, and which, after the necessary adulteration, is to be dissolved in acetic acid, em. ploying a gentle heat to accelerate the action. This acetate of lead may now be examined by means of the hydriodate of potash, when the characteristic appearance will be immediately vresented, even if the quantity operated upon be extremely minuie. I recommend this process chiefly, because it gets rid of one great source of fallacy, viz. the accidental presence of nitric acid. Acetic acid does not interfere with the operation of the test, although it be in considerable excrss ; and this to the inexperienced must be an immense advantage. If, therefore, a suspected fluid yield a black precipitate by the action of sulphusetted bydrogen soluble in nitric acid,-if this nitric solution, on the addition of an alkaline carbonate, afford a white precipitate, soluble in acetic acid; and, lastly, if this acetic solution strike a bright-yellow colour with hydriodate of potash, we have a perfect chain of evidence proving the existence of a saturnine preparation.

In writing this notice, I have no wish to supersede the necessity of the reduction process, for, after all, that is the most accurate test. My object is to present the tyro with a method of employing the hydriodate of potash, should he prefer that mode of investigution, with certainty and success.

I am, Sir, your obedient servant,

London, Jan. 29, 1831.

** Mr. Johnson's process is exceedingly valuable, and will be well worth adopting in any case that may be met with. We may add, that in acting on the sulphuret of lead with nitric acid, heat should not be employed, otherwise a sulphate of lead will be formel. After the application of the hydriodate of soda, it is perfectly easy to reduce the iodide of lead on charcoal with the blow-pipe flame, when the iodine will be expelled, and metallic lead remain, surrounded with the concentric circles of red and yellow oxide, as before described in this Journal.

\section{SUSPICIOUS PRACTICES.}

\section{To the Editor of The Lancet.}

$S_{I R},-K$ nowing (from constantly reading your valuable periodical) your detestation of all quacks, and having noticed in your last number the praseworthy mamer in which jou have exposed some of the per- centage-mongers, I am induced to think the following facts may not be unworthy of yu? notice. First; I should wish to inciuire whether you thmk it very honourable of sir C. S. - to fold up and cirect all h's prescriptions to Mr. Garden, of Oxfird Street, telling his patients that it is the ouly place where the drugs can be had genuine: and secondly, I wish it to be knurn that Mr. V—_ a surgeon of some notoritty at the west end of the town, is constandis in the habit of forcing his patients to take their prescriptions to a certain chemist's situated in Bond Street, between Grosvenor Street and Bruton Street, at the same time telling them that if they go any-wbere else he will not be answerable for the consequences. Do you consider this plan of proceeding re. spectable, or do you believe lie rould take this trouble unless be had an interest in it? But this is not all, for I have seen several instances in which he has translated the pre. scriptions, and desired the people to prepare them at home, by way of depriving apothe. caries or druggists of the advantage of dis. pensing them. Had he only adopted this plan for poor persons it would he excusable, but in all-the instances which bave come under my knowledge it has been done for rich people who could well afford to hare them dispensed at proper places.

January $31,1831$. Amicus Jestrpir.

\section{STEPHENSON AND CHURCHILL'S BOTANT,}

To the Editor of THI: L.tncer. Sir,-I obserse in the last number of THE LAxCeT you have nuticed in terms of cummendation, Mesors. Stephts. son and Churchill's work on Medical Bulary. I have taken it in from the first number, and turee with you, that it is generally well-executed, thinin I think the edicors might have omittcd sunte of the plaris, which cannot be strictly called lirdi. cinal, or such at least as are intruduced inte muten practice. By these omissions much expense wotht have been spared, and the work renderd not lits useful. But the principal cause of my uouldims you on this occasion is tu state, that I wrote sime time since to the editors, making a few iemaing ou one or two of the aricles, and remming them of a pledge they gave to the public, that wil th completion of the work they would give an motu. duction to the study of botany, free ot expense tir che subscibers, and which the ligh price of then publication would amply have enubled them to do. Fhey would by this have increased the ut:lits of then work, and facilitated and promoted thestuh of this plessing science. They bave not thutht proner to notice my letcer, and I therelore undros you, requesting you to make what use of this yul may think necessary. With best whes, beiteit me, sir, yours truly,

Staines, Jan. 20.

Robert Hurter.

AtTorney-Coronnis.-A correspondent obseres on this subject, "As a member of the law 1 w. "d say that the knowledge which is requsite tu the due execution of the ofince of coroner mat bt at.

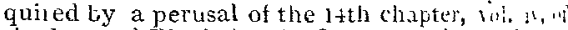
the learned Blackitone's Commentarits, and at is which, I liave no hesitation jn asstrmis if, it ine medical curoner iz ill acquire more jufumatu the suluect than is yossc ssed by thlce-furills wt the

legaly-ciucated cononeis.
"Temple, January, $1831 . "$ 